\title{
The study on the structure of KIBS' innovation ability
}

\author{
ZHAO Gong-min \\ (College of Economics and Management, North University of China, Taiyuan 030051, China)
}

\begin{abstract}
As the KIBS plays a role in the economy, an increasingly important to enhance the ability of KIBS innovation become an urgent issue. Based on innovation foundation, innovation processes and innovation performance in three aspects of performance indicators of construction KIBS innovation system, and by analyzing the research data from three levels of the KIBS in general, two kinds of KIBS and four KIBS industries view of their innovation ability structure studied obtained the current development laws of KIBS's innovation ability. On this basis, the author puts forward the proposal to enhance the structure of KIBS’s innovation ability.
\end{abstract}

Key words: knowledge-intensive business services; innovation; knowledge

\section{Introduction}

With the rise of the knowledge economy, knowledge-intensive services, which provides intellectual support and services for customers by mining, refining, producing and applying a variety of explicit and tacit knowledge resources, has become inevitable in this era. The highly innovative knowledge-intensive business services (referred as KIBS), has been played a leading and driving role in the upgrading of the national economy and regional industrial construction. For example, KIBS contributes as high as 50\% of the GDP in United States, KIBS contributes $22.1 \%$ of the GDP in South Korea (Lee, 2003). These show that currently KIBS plays an unimportant role in the economy of developed countries. In China, the knowledge-intensive industry, including KIBS, accounts for approximately only 7\% of GDP (HU, 2005), far behind the developed countries. The long-standing lack of knowledge of KIBS innovation is a major obstacle. Therefore, improving the study of our KIBS innovation competitiveness becomes an important topic.

The innovation capacity of KIBS is a kind of capacity that the service enterprises with high knowledge-intensive, relying on emerging technologies and expertise, has distinct customer interactive features, apply knowledge, technology, information and other factors to optimize and improve the existing service process and products. The innovation capacity orientation of KIBS is an important way that enterprises recognize and understand their own innovation capacity, it can help the enterprises find the constraints impeding KIBS innovation and verify the law in KIBS innovation process, it is an effective tool to improve the capacity of KIBS innovation. Based on a clear understanding of the constitute of its innovation capacity, it can raises improvement measures corresponding to the shortages, also conducive to make good use of its innovation advantages better, resulting in more efficiently improve the innovation capacity of KIBS.

\section{Literature review}

Since KIBS has been proposed in 1990s, the domestic and foreign scholars have given different definitions

ZHAO Gong-min, Master, professor, College of Economics and Management, North University of China; research fields: marketing innovation and corporate social responsibility. 
from their perspective. Miles proposed that KIBS were engaged in economic activities which aimed at production, accumulation or diffusion of knowledge, and it has three characteristics: (1) The form of organization was mainly private sector and public service organizations; (2) The employees were academics, engineers and other experts with professional knowledge and skills; (3) It provided customers with intermediate products or services with high knowledge content. At the same time, he divided KIBS into two categories: One is traditional professional services, abbreviated as P-KIBS, focuses on new technology users, such as advertising, management consulting and legal services; and the other one is new-technology-based services, abbreviated as T-KIBS, such as software design and other services related to computer information systems (Miles, Kastrinos, Flanagan, Bilderbeek \& Den Hertog, 1995). The key difference between these two types of KIBS is the latter KIBS not only can creatively use the new technologies, but also create new knowledge and technology, which is the greatest contribution made by Miles.

Den Hertog constructed KIBS service innovation model, he proved that KIBS was innovation facilitator, transmission and origin, and he also pointed the new service concept, client interface and service delivery systems and other non-technical factors played important roles in innovation (Den Hertog, 2000). After a lot of research, Tether and Hipp surveyed German Service Sector, especially the sources of KIBS competitiveness and innovation ways, they found that unlike other services innovation statement, KIBS generally spent more on innovation than non-knowledge-intensive counterparts. This means that innovation is important in KIBS (Tether \& Hipp, 2002). Tether and Hipp observed that, through the customized service, KIBS has won a larger proportion of the income than any other service. This means that KIBS innovation activities were product innovation-oriented. They also found that the investment of KIBS was related to innovation (Tether \& Hipp, 2002).

Based on the empirical research, the article will construct the index system of KIBS innovation capacity, and apply the survey data to study the structure of its ability, strive to provide a reliable reference for the improvement of the KIBS innovation capacity.

\section{Research design}

\subsection{Construction of KIBS innovation capacity index system}

Based on the literature collation of researched topic, the research will design a set of evaluation framework and evaluation content for KIBS innovation, after experts discussions and KIBS senior management staff feedback, considering the representation and practical value of the target, it improve the index system, and strive to truly reflect the situation of KIBS innovation from the perspectives of innovation basis, innovation process and innovation performance. Therefore, this paper proposes the specific KIBS innovation indicator system and source, as shown in Table 1.

The system covers the conditions and mechanisms of KIBS innovation service activities, which not only includes funds, facilities, personnel, knowledge base and other characteristics of KIBS, but also gives sufficient attention to KIBS innovation process. As the high innovation performance is the typical characteristic of KIBS, the income and quality of innovative products or services becomes an important indicator to evaluate the innovation, included in index system. The index system can systematically and comprehensively reflect the KIBS innovation capacity, so this paper regards the index system as the standards of KIBS innovation capability assessment. 
The study on the structure of KIBS' innovation ability

Table 1 KIBS innovation capability indicator system

\begin{tabular}{|c|c|c|c|}
\hline First level indicators & $\begin{array}{l}\text { Second level } \\
\text { indicators } \\
\end{array}$ & Explanation & Source \\
\hline \multirow{4}{*}{ Innovation base } & Innovation funds & $\begin{array}{l}\text { Special funds for innovation activities, such as for the development of } \\
\text { new products and services }\end{array}$ & \multirow{4}{*}{$\begin{array}{c}\text { Windrum \& } \\
\text { Tomlinson } \\
\text { (1999), Koch } \\
\text { \& Stahlecker } \\
\text { (2006) }\end{array}$} \\
\hline & Information network & $\begin{array}{l}\text { Network conditions and ancillary equipments required in knowledge } \\
\text { acquisition, retrieval and exchanging }\end{array}$ & \\
\hline & Human resources & $\begin{array}{l}\text { Core personnel, primarily knowledge-based professionals, directly } \\
\text { involved in innovation activities }\end{array}$ & \\
\hline & Knowledge support & Knowledge reservation necessary to conduct daily business & \\
\hline \multirow{4}{*}{ Innovation process } & Customer demand & $\begin{array}{l}\text { Customers' new requirements for the purpose, function and } \\
\text { appearance of its products and services }\end{array}$ & \multirow{4}{*}{$\begin{array}{l}\text { Larsen (2001), } \\
\text { Muller \& } \\
\text { Doloreux } \\
\text { (2009) }\end{array}$} \\
\hline & $\begin{array}{l}\text { Innovation } \\
\text { consciousness }\end{array}$ & $\begin{array}{l}\text { The motivation to create the unprecedented things or ideas to meet } \\
\text { customer needs, which is the novelty intentions and aspirations shown } \\
\text { at the event }\end{array}$ & \\
\hline & Knowledge learning & Actively learning from internal and external to obtain new knowledge & \\
\hline & teamwork & A team, its member cooperates with each other to create synergies & \\
\hline \multirow{2}{*}{$\begin{array}{l}\text { Innovation } \\
\text { performance }\end{array}$} & Innovation revenue & Innovation revenue of new products or new services & \multirow{2}{*}{$\begin{array}{l}\text { Tether \& Hipp } \\
\text { (2002) }\end{array}$} \\
\hline & Quality of service & $\begin{array}{l}\text { The innovative features and performance of products and services can } \\
\text { meet customer needs }\end{array}$ & \\
\hline
\end{tabular}

\subsection{Research methods}

In order to clarify the structure of KIBS innovation, according to the framework of KIBS innovation indicators system, based on the research of the case and the theory, the author designs a set of survey questionnaire to KIBS Innovation. And in accordance with Miles' classification and extent of KIBS, the author carried out the sample household survey for KIBS enterprises from July to August 2009 in Taiyuan, Shanxi Province. The survey interviewed a total of 109 KIBS enterprises to complete the survey and received 105 valid questionnaires, with 56 P-KIBS (traditional professional services)enterprises (including 27 management consulting companies, 29 legal services companies), and 49 T-KIBS enterprises (New-technology-based services) (including 25 software companies, 24 engineering design and consulting companies), the effective rate of questionnaire is $96.33 \%$.

In terms of the structure and content design, the questionnaire is divided into four parts:

Part 1: The purpose and significance of research describe the value and significance of the survey to the respondents and ask them to complete the answers to the questionnaire.

Part 2: Basic information, mainly some information about the surveyed individuals and their enterprises, including the educational background, job title, duties, etc. about of the respondents, and the main business, worker number and service objects of enterprises,.

Part 3: Concept notes, which explain a number of important concepts in the questionnaire, such as innovation capital, knowledge support, knowledge learning, teamwork, innovation revenue and quality of service, in order that the respondents better understand the contents of the questionnaire.

Part 4: The content of questionnaire, which is the body of the questionnaire, the paper design three aspects 10 questions according to Table 1 KIBS innovation index system. The answer to the questionnaire adopted Likert 5 level scale. According to their condition, the enterprises make assessment for the importance of the indicators listed in questionnaire of KIBS innovation, in turn with 5, 4, 3, 2 and 1, which expressed great important, more important, generally, less important and unimportant respectively.

By analyzing the scores of the question on questionnaire, first of all, with its average, we can judge the role 
and performance of index items in KIBS innovation, if the average were high, the indicator of KIBS would have an advantage on its innovation capacity; Secondly, the research use different means of new technology and KIBS innovation relationships, verify the differences between P-KIBS and T-KIBS innovation; Finally, through the comparation of the innovation indicators of different KIBS industries, the paper will get the performance of KIBS innovation capacity in different industries. Based on the above analysis, the paper proposes measures and suggestions to increase the KIBS innovation capacity.

\section{The overall analysis of KIBS innovation structure}

The author firstly statistical analyzes the survey data, from which to understand the general rules of KIBS innovation. Because the different resources and conditions of KIBS generated heterogeneity among enterprises, KIBS is using these dominant resources to meet the different needs of our customers and provide the new service for our customers. KIBS enterprises, involved in research, expressed that in order to enhance brand reputation in knowledge economy, enterprise must provide high quality services for customers with customer-oriented. In order to obtain a sustainable competitive advantage, you must have the strong innovation capacity, to provide innovative services. All Cronbach' Alpha reliability coefficient of indicators in this research has reached more than 0.6, the scale can be considered credible. Table 2 is the descriptive statistics of KIBS innovation capability indicators. The authors figure out the mean and standard deviation of these 10 KIBS innovation indicators, Table 3 shows that the mean was significantly greater than 4 , that is, the more important indicators in knowledge-intensive service innovation are knowledge support, knowledge learning, customer needs, human resources, service quality, innovation revenue, innovation consciousness; Innovation financial and innovation revenue are the general requirements of KIBS innovation capability; Information network, whose mean less than 3, is the indifference of KIBS innovation.

Table 2 Overall statistic results of KIBS innovation capability

\begin{tabular}{|l|c|c|c|}
\hline \multicolumn{1}{|c|}{ Indicators } & Mean & S. D. & N \\
\hline Knowledge support & 4.591 & 0.492 & 105 \\
\hline Knowledge learning & 4.432 & 0.539 & 105 \\
\hline Customer demands & 4.341 & 0.638 & 105 \\
\hline Human resources & 4.318 & 0.791 & 105 \\
\hline Service quality & 4.273 & 1.031 & 105 \\
\hline Teamwork & 4.068 & 0.939 & 105 \\
\hline Innovation consciousness & 4.023 & 0.866 & 105 \\
\hline Innovation financial & 3.364 & 1.150 & 105 \\
\hline Innovation revenue & 3.318 & 0.847 & 105 \\
\hline Information network & 2.818 & 0.860 & \\
\hline
\end{tabular}

Knowledge support and knowledge learning, with the highest score, are the most important content in the assessment of KIBS innovation capability. This is in line with the knowledge-intensive characteristics of KIBS. Seeing knowledge support as the background is not only the first condition that customers choose enterprises, but also the base that customers trust KIBS innovation. The knowledge learning is closely related to knowledge support, they are the service depot for KIBS to achieve service innovation. Only constantly acquire new knowledge that you can find new methods and new skills to furnish service innovation. In the age of knowledge economy, capital investment and benefits are no longer the sole criterion to prove enterprise strength. We can see 
from the above data analysis that the lower score of the two indicators explains most input and output of KIBS capital only reflects its innovation capability in a certain extent. As KIBS innovation materialization is not obvious in infrastructure, the utilization rate of rapid developing network and information technology in KIBS is not high, so in the future, we should accelerate the applications of means of communication to access knowledge and spread knowledge, and develop the appropriate information management system to improve the role of information networks in KIBS innovation process. In addition, the standard deviations of innovation financial and service quality are high, which indicates that the gap of the survey data in these two indicators is relatively large. Because different enterprise attach different importance to these two indicators, which requires further research about KIBS.

\section{Structural analysis of two types of KIBS innovation}

KIBS is a kind of production service which regards knowledge as the main input factor, its high innovation performance significantly depends on the application of their acquired knowledge and skills to provide services and products with high knowledge ingredients. To better understand the characteristics of various innovation indicators in P-KIBS and T-KIBS, we conduct means comparation and T-test for P-KIBS and T-KIBS. We can observe from Fig. 1 that, knowledge support scores high in two types of KIBS industry, which proves that it is a key factor in knowledge innovation. From the overall indicator system, P-KIBS pays more attention to knowledge-based talent, but because of other services flexible and relatively strong dependence on the experience, it emphasizes less on the information network and innovation capital. The significance of T-KIBS innovation indicators tends to balance, because T-KIBS pays more attention to the innovation process, a lot of innovation is implicit knowledge, only demonstrate in the course of providing services.

With the features of creative use of new knowledge and new technologies, P-KIBS focuses more on corporate talent and knowledge support, because knowledge support is the knowledge reservation of P-KIBS industry. As the master of P-KIBS knowledge, corporate talent are the perpetrators of innovative business services, both knowledge support and corporate talent are the core resources of P-KIBS. As shown in Fig. 1, the values of the two indicators are not only higher than that of T-KIBS, but also the highest average score throughout the index system of the innovation capability, proves to be the very important content in P-KIBS innovation. Management consulting and legal services fully rely on the knowledge and skills stored by knowledge support and knowledge-based talents, such knowledge system of the industry are basically completed and mature. As the innovation capital and information networks couldn't improve innovation capacity directly, these two indicators score low. Such enterprises believe that in order to innovate constantly, one should acquire new knowledge and new technologies.

T-KIBS is based on new technology and has shifted from technical support output to technical incubate output, which KIBS strategically upgrade the functions of the new technology. Therefore, the service innovation relating to software designation and other computer information systems requires more investment and advanced machinery and equipments, which not only support T-KIBS business, but also derivation for the promotion of its new technological achievements. So, these two indicators are significantly higher than that of P-KIBS, which is consistent with the actual. Especially innovation financial, including a substantial increase in research investment, is the most obvious indicator in T-KIBS. At the same time, we can found that, for T-KIBS, customer demands and quality of service are the most important indicators to reflect the innovation capability of the industry, one of the two indicators is the requirement for the innovative of products and services, and the other is the test for the 
innovative of products and services. Customer demand is the baton of enterprise, it proposes new demands to T-KIBS at any time. Under its guidance, enterprises constantly learn, excavate, integrate the business knowledge and technology to improve its innovation capacity to create new knowledge products. Providing satisfacted services and high quality products to customer is the purpose of enterprise, good quality of service necessarily requires T-KIBS innovation, which is the most direct expression of its innovation capacity.

In innovation performance, the two types of KIBS pay more attention to the quality of final products and services than innovation revenue, that is, the amount of innovation contained in new products and services, which reflects KIBS innovation capacity from the perspective of innovation results. As the characteristics of knowledge economy, innovation level and capability can not be simply measured by revenue. Although KIBS regards profit as its final goal, it provides products and services with the characteristics of high knowledge content and difficult to accurate evaluate, so, innovation revenue can't reflect the potential value of innovative ingredients of the KIBS innovative products and services. The data further show that, for innovation capability, T-KIBS pays more attention to performance indicators than P-KIBS, the development of high-tech innovation want a higher yield and return.

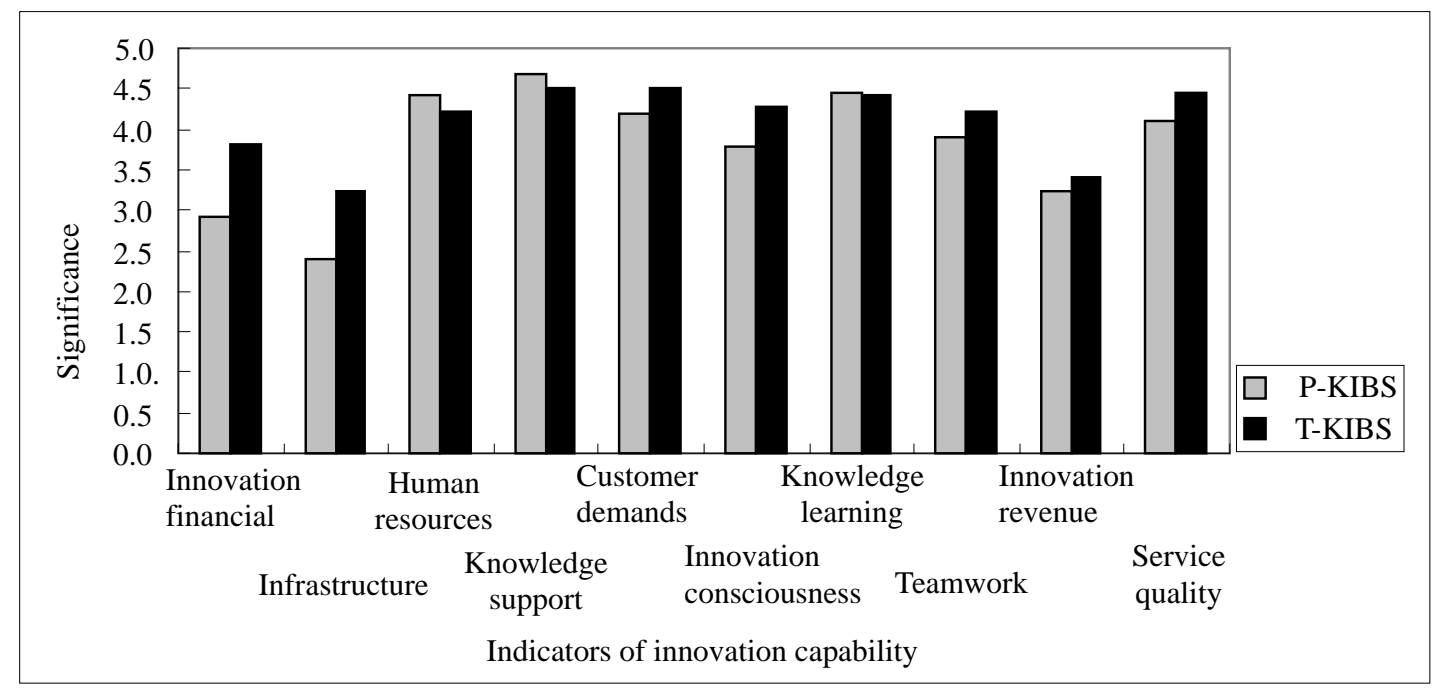

Fig. 1 P-KIBS and T-KIBS innovation capability comparison

The results of $T$ test to independent samples of P-KIBS and T-KIBS in Table 3 show that: (1) In innovation, these two types of KIBS pay different attention to innovation funds (Two-tailed significance probability $=0.006<0.01$ ) and information networks (Two-tailed significant probability $=0.002<0.01$ ), the difference is very significant. The services provided by P-KIBS enterprises are mostly standardized and programmed, innovation investment and information network construction play less important roles on the improvement of innovation capacity, leading to innovative applications mainly in services and products, lack of primary innovation, which is the common phenomenon of P-KIBS. The innovation results, provided by T-KIBS, require a large number of research funds and the application of advanced instruments and equipments to complete the development of new technologies and new knowledge. This also explains the difference of innovation investment between P-KIBS and T-KIBS which affects innovation capability. (2) Two-tailed significance probability of innovation consciousness is 0.038 , indicating that the difference between P-KIBS and T-KIBS is significant in this indicators. The business activities, in which P-KIBS enterprises engaged, restrict the innovation space and consciousness, lacking of innovation awareness is the reason why our KIBS particular P-KIBS innovation lag behind initiative. 
The study on the structure of KIBS' innovation ability

Table 3 P-KIBS and T-KIBS innovation capability comparison

\begin{tabular}{|l|c|c|c|}
\hline \multicolumn{1}{|c|}{ Indicators } & P-KIBS & T-KIBS & Sig.(2-tailed) \\
\hline Innovation financial & 2.91 & 3.82 & $0.006^{*}$ \\
\hline Information networks & 2.41 & 3.23 & $0.002^{*}$ \\
\hline Human resources & 4.41 & 4.23 & 0.329 \\
\hline Knowledge support & 4.68 & 4.5 & 0.213 \\
\hline Customer demands & 4.18 & 4.5 & 0.129 \\
\hline Innovation consciousness & 3.77 & 4.27 & $0.038^{* *}$ \\
\hline Knowledge learning & 4.45 & 4.41 & 0.803 \\
\hline Teamwork & 3.91 & 4.23 & 0.184 \\
\hline Innovation revenue & 3.23 & 3.41 & 0.463 \\
\hline Quality of service & 4.09 & 4.45 & 0.236 \\
\hline
\end{tabular}

Notes: ** stands for $\mathrm{P}<0.05$; * stands for $\mathrm{P}<0.01$.

\section{Innovation capability structural analysis of 4 KIBS industries}

The significance comparison of the KIBS innovation indicators in four sectors of KIBS, is shown in Table 4. Overall, these 4 KIBS industries attach great importance to knowledge management, because knowledge support and knowledge learning are in the forefront of the indicators. With the main inputs of knowledge and through learning, processing, mining and innovating, KIBS produces knowledge products to meet customers demands. Therefore, the characteristic of the data not only reflects the nature of KIBS, but also further proves that these four industries are typical KIBS industries. At the same time, customer demand indicators are significant, which verifies Porter's view that the critical client is an important driving force of industrial development, and it is also right in KIBS sector.

Table 4 Comparison of innovation indicators of different industries

\begin{tabular}{|l|l|l|l|l|l|l|l|c|}
\hline \multicolumn{2}{|c|}{ Legal services industry } & \multicolumn{2}{|c|}{ Management consulting industry } & \multicolumn{2}{c|}{$\begin{array}{c}\text { Engineering designing and } \\
\text { consulting industry }\end{array}$} & \multicolumn{3}{c|}{ Software industry } \\
\hline Knowledge support & 4.909 & Knowledge support & 4.455 & Knowledge support & 4.417 & Knowledge learning & 4.7 \\
\hline Knowledge learning & 4.545 & Human resources & 4.364 & Customer demands & 4.417 & Knowledge support & 4.6 \\
\hline Human resources & 4.455 & Knowledge learning & 4.364 & Quality of service & 4.417 & Customer demands & 4.6 \\
\hline Customer demands & 4.091 & Customer demands & 4.273 & Human resources & 4.250 & $\begin{array}{l}\text { Innovation } \\
\text { consciousness }\end{array}$ & 4.6 \\
\hline Quality of service & 4.000 & $\begin{array}{l}\text { Innovation } \\
\text { consciousness }\end{array}$ & 4.273 & Knowledge learning & 4.167 & Quality of service & 4.5 \\
\hline Teamwork & 3.727 & Quality of service & 4.182 & Teamwork & 4.083 & Innovation financial & 4.5 \\
\hline $\begin{array}{l}\text { Innovation } \\
\text { consciousness }\end{array}$ & 3.273 & Teamwork & 4.091 & $\begin{array}{l}\text { Innovation } \\
\text { consciousness }\end{array}$ & 4.000 & Teamwork & 4.4 \\
\hline Innovation revenue & 3.182 & Innovation revenue & 3.273 & Information networks & 3.333 & Human resources & 4.2 \\
\hline Innovation financial & 2.636 & Innovation financial & 3.182 & Innovation revenue & 3.333 & Innovation revenue & 3.5 \\
\hline Information networks & 2.364 & Information networks & 2.455 & Innovation financial & 3.250 & Information networks & 3.1 \\
\hline
\end{tabular}

In Table 4, from left to right, from the legal services to the software industry in this direction, the services provided by KIBS change from personalized and differentiated to standardized and modular, further to customized, the data in the table has the following rules:

First, the importance of human resources decline, but this not means KIBS pays less and less attention to knowledge-based employees. As any indispensable backbone of KIBS innovation, knowledge-based workers directly involve in innovation activities. Now his work experience and tacit knowledge can be summed up as a file or 
standard, so, this transforms the knowledge stored in human mind into the machine identification information, which not only adds valuable wealth of knowledge into the existing KIBS knowledge system, but also facilitate knowledge management. It is because the stored knowledge of KIBS has been extended, and easier use and management of the importance of human resources declines in Table 4, but the relatively value of importance isn't significantly reduced, which reflects the important trends of intelligent management and decision-making in knowledge economy.

Second, teamwork is still very important, but because of the characteristics of services, the way of teamwork has been changed. Team is composed by business units, it regards flexible and informal communication as the main means of communication, which facilitate to acquire tacit knowledge and propose different programs. For project-centered, the author implements official communication of centralized meeting for teamwork, which is easy to define questions, share knowledge and propose practical technology solutions and new application designations. As for the software industry, both the development of general software and customized software have been replaced by network communication, the emergence of virtual cooperation makes teamwork more flexible and efficient. KIBS innovation can not be achieved by individual employees, teamwork is the cornerstone of KIBS, and only the collective knowledge of teamwork can enhance the KIBS innovation capability.

Third, the improvement of the importance of service quality shows that the products and services innovation content has been increased in the four industries. In Table 4, from legal advice conclusions, management advisory reports, engineering designation program to software products, the innovation composition are more and more concerned by customers. The organization pays more attention to the innovation, which drive QOS index increase.

\section{Important inspirations to optimize the structure of KIBS innovation}

From three levels of general, classified and specific industries, the research described and analyzed KIBS innovation capability structure. Then, it obtained some development laws of KIBS innovation. In order to guide rapidly and healthy development of KIBS, and promote the enhancement of KIBS innovation capability, the research initially proposed the following measures to optimize the structure of KIBS innovation:

Firstly, we should strengthen the knowledge management of KIBS, and consolidate the basis of KIBS innovation. According to the information of British knowledge management journal, knowledge management can significantly improve the capability of KIBS innovation. Based on the limited use of knowledge currently, the improvement of knowledge management not only makes KIBS fully identify its knowledge, but also consolidates, transfer and manage the knowledge to effectively use knowledge and obtain a competitive advantage. Knowledge management provides a public platform of knowledge resource pooling, crossing, fashioning, mutating and producing innovation for the KIBS. With the knowledge sharing and learning within the organization, KIBS is transformed from a passive mechanical system to a self-driven, self-regulating, self-learning, self-transcendence agent. We construct the flexible organizational structure to support knowledge management in KIBS, create organizational culture for knowledge management, pay more attention to knowledge management investment, which are bound to play an important role in strengthening the basis of KIBS innovation capability.

Secondly, we should develop KIBS innovation incentives to promote the process of KIBS innovation. Lack of innovative motivation is the main obstacle to improve innovation capacity currently. As is known to all, innovative talents play a main role in independent innovation activities, how to effectively motivate them is the core of KIBS management activities. It is imperative to formulate effective measures to stimulate KIBS innovation, which promotes the talent to play their initiative and conscious, actively involved in innovative 
activities, to enhance the transfer speed and efficiency of knowledge in organizations. In order to create an atmosphere to encourage the freedom of innovation, KIBS could develop multi-level, systematic incentive systems and competitive pay policies to satisfy the needs of innovative technical talents, and provide the challenging work content, thus, stimulate the enthusiasm, initiative and creativity of the innovative talents. Through a series of incentives to stimulate innovation consciousness of KIBS and the formation of KIBS innovation team, KIBS innovation will be rapidly developed during the service process.

Thirdly, we should develop KIBS innovative information systems, comprehensively develop KIBS innovation environment. In order to reasonably arrange the investment of KIBS innovation environment, we should pay more attention to "hardware" and "software". The advanced information technology is the accelerator of knowledge and technological innovation. It is proved that it can not only improve the speed of knowledge diffusion, knowledge integration and knowledge crossing, but also transform the local centralized innovation into a flexible, remote and scattered innovation. On the one hand, the current complex and volatile environment requires the use of advanced information technology to design and develop relational database systems in which a lot of knowledge could be stored; to design and develop information systems which can improve the knowledge processing capacity; to design and develop knowledge management system which can support experts' decision. It also uses dynamic point of view to research the emerging new problems. The improvement of KIBS innovation capability is constant, but we must pay attention to real-time, any outdate innovation results will be greatly devalued, so, we should use information technology and information management systems to high-speed and efficient producing to seize the market, obtain the maximum benefits. On the other hand, KIBS should update the traditional "on paper" concept. With communications technology, we should cultivate and maintain the mutual cooperated KIBS partnerships, formed complementary knowledge networks as soon as possible. At present, only the establishment of mutual benefit long-term relationship with the wisdom of pooled multidisciplinary, $\mathrm{t}$ can solve increasingly complex problems to achieve the purpose of innovation.

Fourth, we should improve the evaluation mechanism of innovation performance, fully promote KIBS innovation. The characteristics that KIBS provides high knowledge content products and services determine the innovation performance is not only reflected in the quantity of innovations, but also reflected in the quality. Quantity refers to the amount of innovation revenue in products and services; quality refers to the amount of innovative content (its advanced nature) in products and services. In order to study the innovative capability of KIBS, we should develop and formulate a scientific and reasonable KIBS innovation performance management system to comprehensive, objective and accurate evaluate the effect of KIBS innovation. According to the evaluation results, we found the difference of the quantity and quality in innovative content, fair reward and punish, which targeted to help the improvement of KIBS innovation capability in the future.

\section{References:}

Den Hertog, P. D.. (2000). Knowledge-intensive business services as co-producers of innovation. International Journal of Innovation Management, 4(4), 491-528.

HU, A, G.. (2005, April 21). Build the largest knowledge-based society. Shenzhen Economic Daily.

Lee, K. R.. (2003). Knowledge intensive service activities (KISA) in Korea’s innovation system. OECD Report, 2.

Miles, I., Kastrinos, N., Flanagan, K., Bilderbeek, R. \& Den Hertog, P.. (1995). Knowledge-intensive business services: users, carriers and sources of innovation. Luxembourg: European Innovation Monitoring Systems (EIMS), Publication No 15, 18

Tether, B. S., Hipp, C.. (2002). Knowledge intensive, technical and other services: patterns of competitiveness and innovation compared. Technology Analysis \& Strategic Management, 14(2), 163-182.

(Edited by Ruby and Chris) 